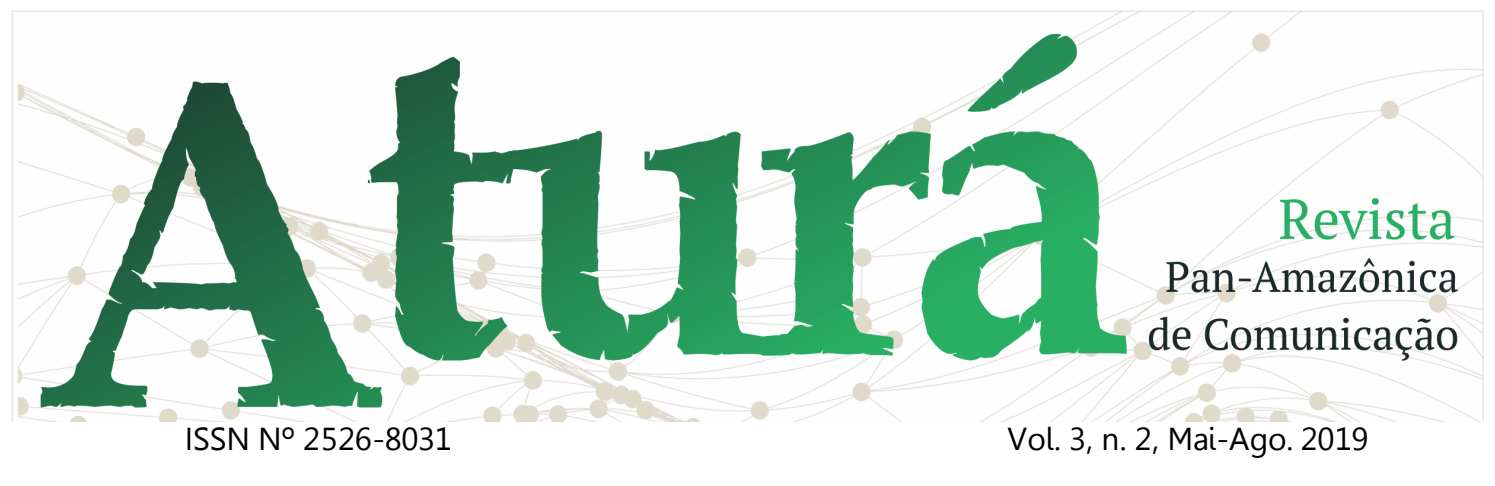

\title{
DISCUSSÕES SOBRE RESÍDUOS SÓLIDOS NA MÍDIA REGIONAL
}

Discussions on solid waste in regional media

Discusiones sobre residuos sólidos en medios regionales

\section{Lucas Braga da Silva ${ }^{1}$}

\section{RESUMO}

A Política Nacional de Resíduos Sólidos, Lei n 12.305/2010 aponta a elaboração de planos de resíduos sólidos pelos estados brasileiros como um instrumento de gestão e gerenciamento. A pesquisa discute a elaboração deste instrumento da política no território tocantinense a partir de material jornalístico publicado por veículos online da mídia regional. A pesquisa é de abordagem qualitativa e que adota a análise de conteúdo na análise dos dados coletados. Diante do exposto, a conclusão é de que durante este processo alguns veículos da mídia apresentaram dados e informações relacionadas ao assunto, mas em alguns casos sem muitos detalhes e nem todos os momentos da elaboração do plano foram retratados.

PALAVRAS-CHAVE: Resíduos Sólidos; Mídia Regional; Participação Social; Mobilização Social.

\section{ABSTRACT}

The National Policy on Solid Waste, Law No. 12,305 / 2010 points to the preparation of solid waste plans by the Brazilian states as a management and management tool. The research discusses the elaboration of this instrument of politics in the Tocantins territory

1 Graduado em Tecnologia em Logística pelo Instituto Federal do Tocantins. Graduado em Administração pela Universidade Federal do Tocantins. Especialista em Docência do Ensino Superior pela Universidade Norte do Paraná. Mestrando em Comunicação e Sociedade pela Universidade Federal do Tocantins. E-mail: lucasilva119@hotmail.com. 


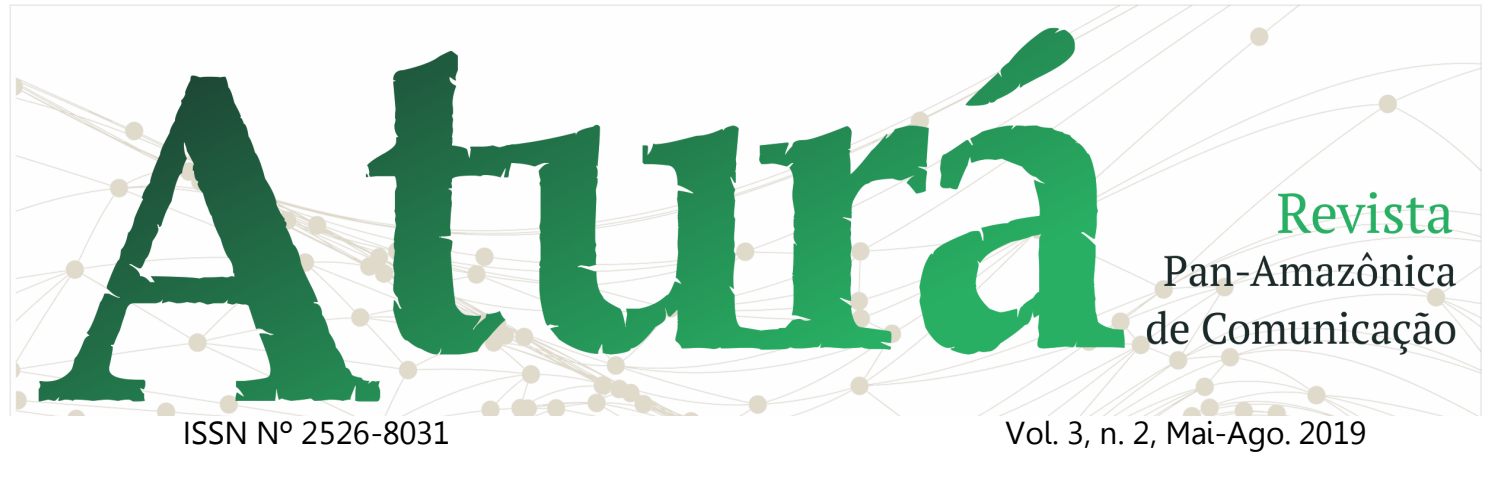

from journalistic material published by online media of the regional media. The research is qualitative approach and adopts content analysis in the analysis of collected data. Given the above, the conclusion is that during this process some media outlets presented data and information related to the subject, but in some cases without much detail and not all moments of the preparation of the plan were portrayed.

KEYWORDS: Solid waste; Regional Media; Social Participation; Social mobilization.

\section{RESUMEN}

La Política Nacional sobre Residuos Sólidos, Ley No. 12.305 / 2010, apunta a la preparación de planes de residuos sólidos por parte de los estados brasileños como una herramienta de gestión y gestión. La investigación discute la elaboración de este instrumento de política en el territorio de Tocantins a partir de material periodístico publicado por medios en línea de los medios regionales. La investigación es un enfoque cualitativo y adopta el análisis de contenido en el análisis de los datos recopilados. Dado lo anterior, la conclusión es que durante este proceso, algunos medios de comunicación presentaron datos e información relacionados con el tema, pero en algunos casos sin muchos detalles y no todos los momentos de la elaboración del plan fueron retratados.

PALABRAS CLAVE: Residuos sólidos; Medios regionales; Participación social; Movilización social.

Recebido em: 19.02.2019. Aceito em: 24.04.2019. Publicado em: 01.05.2019. 


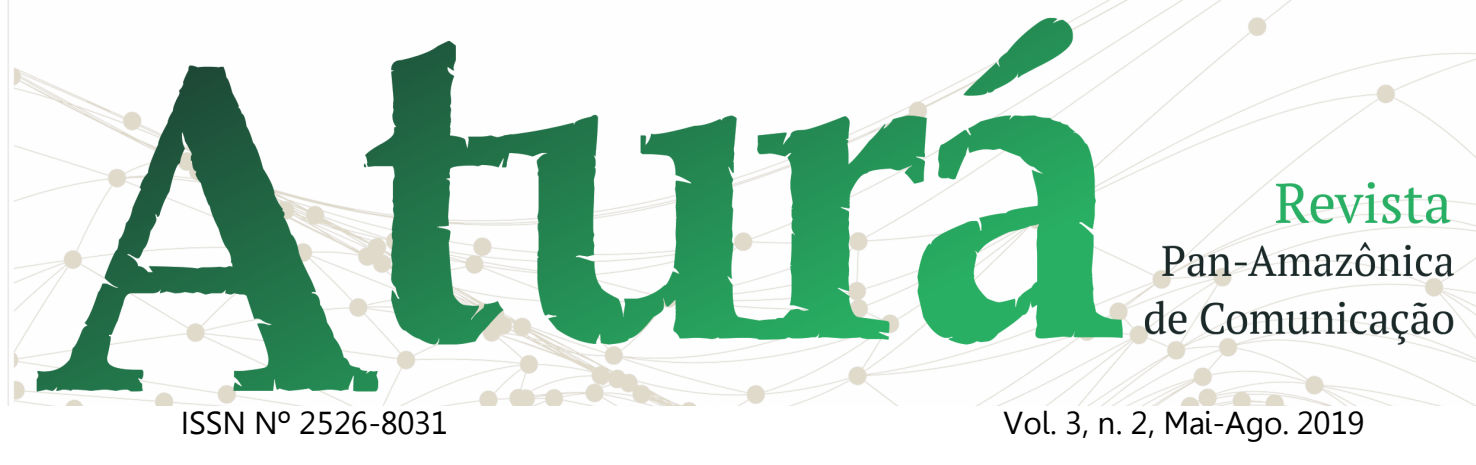

\section{Introdução}

A elaboração de planos de resíduos sólidos por todo o território brasileiro, como o nacional, os estaduais, os microrregionais, os de regiões metropolitanas ou aglomerações urbanas, os intermunicipais, os municipais de gestão integrada e os de gerenciamento consta na Política Nacional de Resíduos Sólidos (PNRS), dada pela Lei $n^{\circ}$ $12.305 / 2010$ como um instrumento para a gestão e o gerenciamento de resíduos sólidos (BRASIL, 2010).

Apenas $52 \%$ das 27 unidades federativas brasileiras, $31 \%$ dos 5.570 municípios brasileiros e 40\% dos 139 municípios tocantinenses conseguiram se adequar ao requisito de elaboração dos planos de gestão de resíduos sólidos até o ano de 2012 (OBSERVATÓRIO DOS LIXÕES, 2019).

Ainda a política retrata que a administração pública durante a elaboração destes deve instituir consultas e audiências públicas tendo em vista a participação de atores estatais e não estatais nesta arena de debates. Além de também garantir o acesso ás informações e a respectiva publicidade de dados que retratem deste contexto e o controle social (BRASIL, 2010).

A política destaca que os planos estaduais devem abordar aspectos como o diagnóstico da situação dos resíduos sólidos, os impactos socioeconômicos e ambientais da disposição e destinação inadequada destes, a coleta seletiva, a recuperação e a reciclagem de materiais, o tratamento e a disposição adequada destes, a gestão e o gerenciamento dos mais variados tipos de resíduos sólidos. Além de também apresentar o zoneamento de área para identificar áreas adequadas para $\mathrm{o}$ tratamento $\mathrm{e}$ disposição de resíduos e as respectivas áreas degradadas (BRASIL, 2010).

A participação da sociedade civil e de empresas públicas e privadas durante a elaboração dos planos de resíduos sólidos em todo o território brasileiro deve ser mobilizada a partir dos diversos canais de comunicação tendo em vista atingir um maior número de pessoas (BRASIL, 2010). Pires e Vaz (2012) complementam afirmando que a participação e a interação da sociedade civil, de grupos específicos da sociedade e de empresas privadas nas etapas de formulação, implementação e avaliação de políticas possibilita a legitimidade deste processo.

A publicidade de dados e o controle social do conteúdo dos planos de resíduos sólidos deve ocorrer tanto na etapa de elaboração como de implementação e operacionalização (BRASIL, 2010). Cezar (2018) explica que a publicidade de dados pode ser vista 


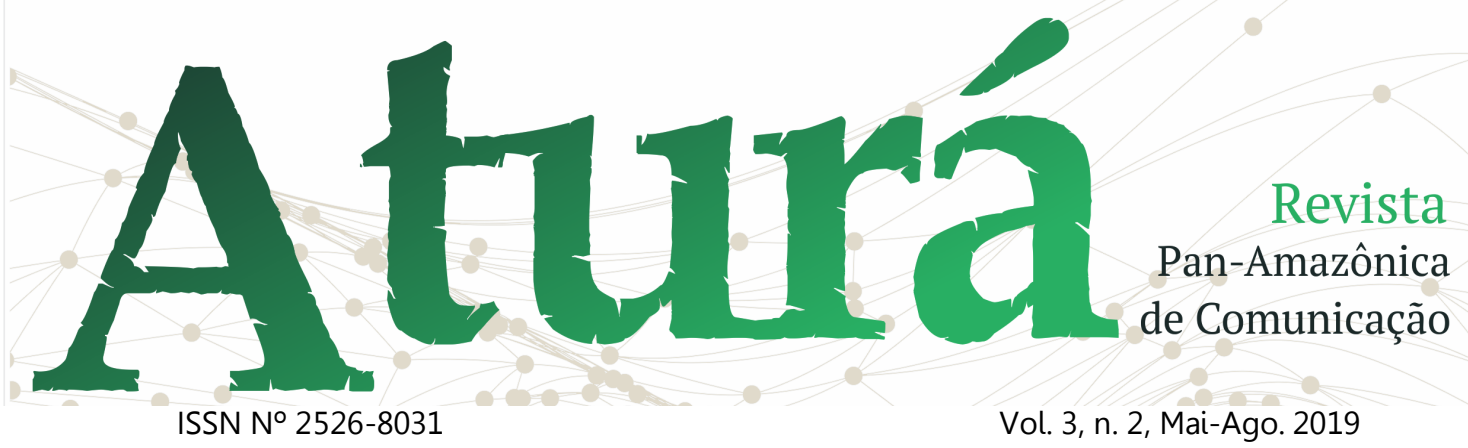

como uma maneira das agências governamentais divulgarem as etapas do ciclo de determinada política pública e mobilizar os diferentes atores sociais para participar dos debates instituídos neste cenário.

Esta pesquisa considera a implementação de um dos instrumentos da PNRS, o Plano Estadual de Resíduos Sólidos do Tocantins (PERS/TO), especialmente o contexto de elaboração que compreendeu os anos de 2015 a 2017. Para tanto, a Secretaria Estadual de Meio Ambiente e Recursos Hídricos (SEMARH) deste estado adotou alguns mecanismos de expressão e diálogo, sendo eles as oficinas técnicas, as audiências públicas e o seminário estadual de resíduos sólidos (TOCANTINS, 2017).

Teixeira et al. (2018) apontam que a mobilização de diversos setores e segmentos da sociedade com vistas a participação e a interação destes nas arenas de elaboração, implementação e operacionalização de políticas públicas ocorre devido a disponibilidade de informações a respeito deste processo por parte dos veículos da mídia local e até mesmo das agências governamentais.

A mídia impressa, televisiva, radiofônica e digital corroborara para a publicidade de dados tendo em vista a mobilização de atores sociais e a divulgação de dados referentes as

modalidades participativas instituídas durante a elaboração deste plano de resíduos (TOCANTINS, 2015). Para Lima (2008) a mídia regional apresenta neste contexto dados e informações aos distintos grupos da sociedade que retratem do território de pertencimento e da identidade de determinada localidade.

De modo geral, a pesquisa discute a elaboração do PERS/TO a partir de material jornalístico publicado por veículos online da mídia regional, a fim de verificar a atuação dos veículos de notícias de Palmas no que diz respeito a divulgação de dados e informações sobre os processos de participação instituídos, tais como oficinas técnicas, audiências públicas e o seminário estadual de resíduos sólidos. Esta pesquisa está estruturada em cinco tópicos, sendo a introdução que aborda a problemática e objetivos da pesquisa, a parte de revisão de literatura que retrata de abordagens ligadas a participação social, mídia regional, mobilização social e ao PERS/TO, a metodologia adotada para a realização desta, a análise e discussão dos dados coletados e as considerações finais.

\section{O plano de resíduos sólidos do Tocantins}

A participação e expressividade da sociedade civil e das agências governamentais e empresariais pode ocorrer através dos conselhos gestores de políticas públicas, conferências temáticas, 


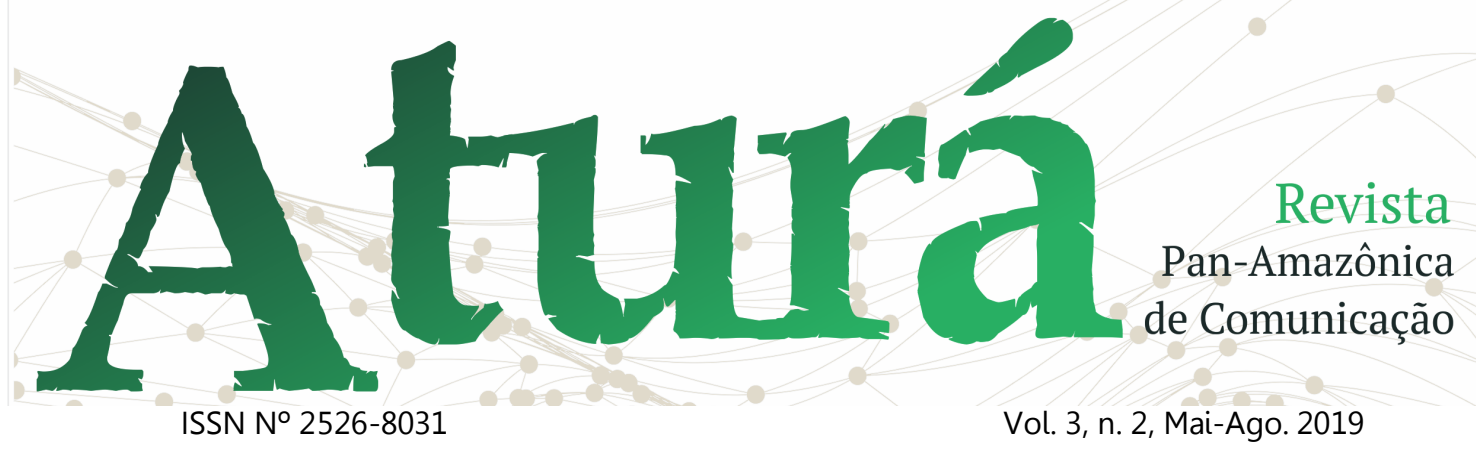

audiências e consultas públicas, entre outras possibilidades (PIREZ; VAZ, 2012). A política de resíduos sólidos exige a institucionalização de audiências e consultas públicas no contexto de elaboração dos planos (BRASIL, 2010). As audiências públicas consistem em encontros presenciais para instigar a participação da sociedade civil e de outros grupos para debater a respeito de uma determinada temática de interesso coletivo. Já as consultas públicas objetivam estruturar sistemas de votação e colaboração a distância para debater temáticas específicas (PIREZ; VAZ, 2012).

De acordo com Pires e Vaz (2012) as redes e canais instituídos aspirando a participação e a interação entre as agências governamentais e a sociedade civil favorece de modo eficiente e eficaz a responsividade e a transparência das decisões públicas relacionadas a programas e políticas públicas desenvolvidas. Ademais viabiliza a inclusão e o envolvimento de grupos distintos da sociedade, agentes políticos e econômicos na gestão de políticas públicas (GOMIDE; PIRES, 2014).

Gomide e Pires (2014) percebem a inclusão de diferentes atores nas arenas de debates institucionalizadas pela administração pública como necessária para, por exemplo, adquirir dados e informações relevantes para o enfrentamento de problemáticas distintas vivenciadas em determinada localidade e, por conseguinte, apresentar respostas inovadoras neste sentido. A inclusão de atores estatais e não estatais na tomada de decisão pública corrobora para a qualidade e legitimidade deste processo. As discussões diversificadas acerca de determinada política pública corroboram para resultados mais satisfatórios durante o seu desenvolvimento.

O processo de elaboração do PERS/TO constituiu-se em cinco metas integrantes. A primeira denominada de Fase Meta 1 - apresentou um relatório das oficinas técnicas realizadas em 18 áreas programas do estado (ver quadro 1). Para a elaboração deste documento foram realizadas oficinas técnicas no período de 22 de setembro a 29 de outubro de 2015 nestas regionais. Além de audiências públicas nos municípios de Araguaína, Gurupi e Palmas onde discutiram sobre uma versão preliminar deste plano (TOCANTINS, 2015, grifo nosso). E, para refletir as discussões destas audiências e também concluir a escrita do plano, houve a realização de um seminário estadual de resíduos sólidos na cidade de Palmas no mês de junho de 2017 para apresentar a sua versão final (TOCANTINS, 2017, grifo nosso).

Quadro 1: Áreas programas e respectivos municípios. Fonte: Adaptado de Tocantins (2016, p. 59-60). 


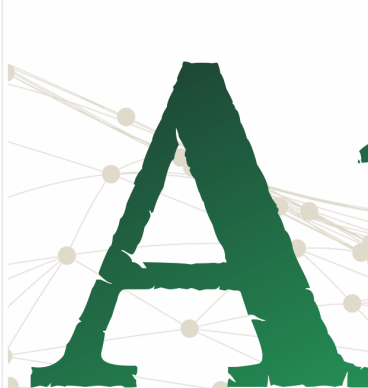

ISSN N $2526-8031$

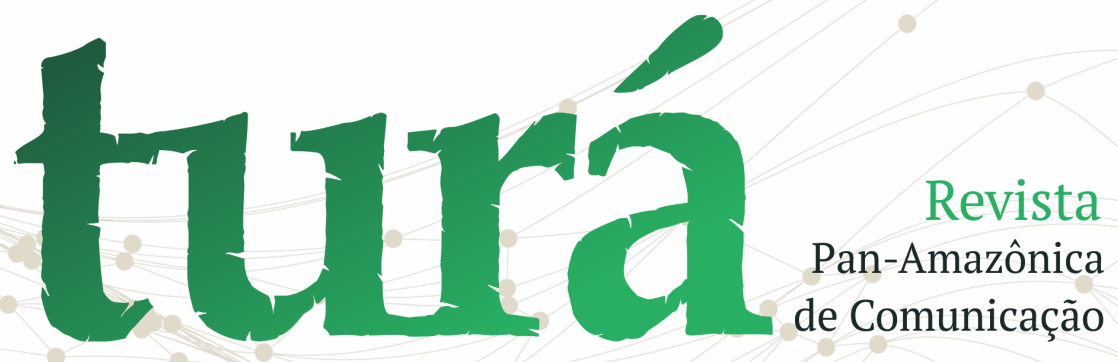

Vol. 3, n. 2, Mai-Ago. 2019

\begin{tabular}{|l|l|}
\hline No & $\begin{array}{l}\text { Área } \\
\text { programa }\end{array}$ \\
\hline 1 & Araguatins \\
\hline 2 & Tocantinópolis \\
\hline
\end{tabular}

Municípios

Cachoeirinha, Esperantina, São

Bento do Tocantins, São

Sebastião do Tocantins;

Aguiarnópolis, Angico,

Darcinópolis, Itaguatins,

Luzinópolis, Maurilândia do

Tocantins, Nazaré, Palmeiras do

Tocantins, Santa Terezinha do

Tocantins;

Aragominas, Babaçulândia,

Carmolândia, Filadélfia,

3 Araguaína Muricilândia, Nova Olinda,

Palmeirante, Santa Fé do

Araguaia, Wanderlândia;

4 Arraias

Combinado, Conceição do

Tocantins, Novo Alegre

Axixá do Tocantins, Buriti do

Tocantins, Carrasco Bonito, Praia

5 Augustinópolis Norte, Sampaio, São Miguel do

Tocantins, Sítio Novo do

Tocantins;

Arapoema, Bandeirantes do

Tocantins, Bernardo Sayão,

Colinas do Brasilândia do Tocantins, Couto Tocantins Magalhães, Itaporã do Tocantins, Juarina, Pau D'Arco, Pequizeiro, Presidente Kennedy, Tupiratins; Almas, Novo Jardim, Porto

7 Dianópolis Alegre do Tocantins, Rio da Conceição, Taipas do Tocantins

8 Goiatins Barra do Ouro, Campos Lindos;

Araguacema, Colméia, Dois Irmãos do Tocantins, Fortaleza

9 Guaraí do Tabocão, Goianorte, Miranorte, Rio dos Bois, Tupirama

Aliança do Tocantins, Alvorada,

10 Gurupi Araguaçu, Cariri do Tocantins,

Crixás, Dueré, Figueirópolis,
Formoso do Araguaia, Jaú do

Tocantins, Peixe, Sandolândia,

Sucupira, Talismã

Chapada da Natividade,

11 Natividade

Pindorama do Tocantins, Santa

Rosa do Tocantins, São Valério da Natividade, Silvanópolis

Lagoa do Tocantins, Lizarda,

Mateiros, Ponte Alta do

12 Novo Acordo Tocantins, Rio Sono, Santa Tereza do Tocantins, São Félix do

Tocantins

Aparecida do Rio Negro, Brejinho de Nazaré, Fátima, Ipueiras,

Lajeado, Miracema do Tocantins, Monte do Carmo, Oliveira de

Fátima, Porto Nacional,

Tocantínia

14 Paranã

Palmeirópolis, São Salvador do

Tocantins

Abreulândia, Barrolândia,

Caseara, Chapada de Areia,

Cristalândia, Divinópolis do

15 Paraíso do Tocantins, Lagoa do Confusão,

Tocantins Marianópolis do Tocantins,

Monte Santo do Tocantins, Nova

Rosalândia, Pium, Pugmil, Santa

Rita do Tocantins

Bom Jesus do Tocantins,

16 Pedro Afonso

Centenário, Itacajá, Itapiratins,

Recursolândia, Santa Maria do

Tocantins

17 Taguatinga

Aurora do Tocantins, Lavandeira, Ponte Alta do Tocantins

Ananás, Araguanã, Piraquê, Riachinho

A Fase Meta 2 compreendeu a apresentação de um panorama geral dos resíduos sólidos do estado. A Fase Meta 3 


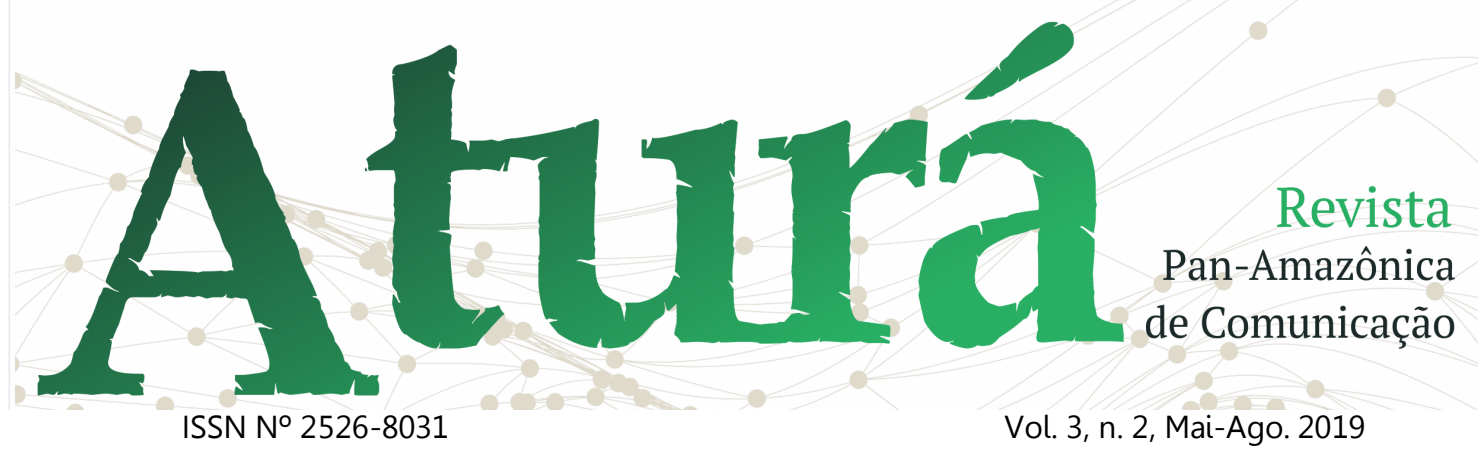

retratou um estudo sobre a regionalização da prestação de serviços de manejo de resíduos sólidos para identificar arranjos territoriais dos municípios. $\mathrm{E}$, através disso, possibilitar o compartilhamento de serviços e otimizar recursos financeiros, humanos e de infraestrutura.

A Fase Meta 4 apresenta um estudo de prospecção para a escolha de um cenário de referência. Nesta fase foram descritos os princípios adotados na elaboração de um quantitativo de três cenários e os respectivos resultados obtidos. Foi escolhido o cenário que considera o crescimento da economia brasileira, de 2015 a 2019 com Produto Interno Bruto (PIB) de 1,8\% a.a. e de 2020 a 2024 de 4,5\% a.a. Detalhando um pouco mais, a Fase Meta 5 - trouxe um planejamento para a implementação do PERS/TO que definiu diretrizes e estratégias para a elaboração deste (TOCANTINS, 2017, grifo nosso).

Para Teixeira et al. (2018) a elaboração de um plano de gestão integrada de resíduos sólidos é vista como um processo que exige a participação e a inclusão de representantes da sociedade civil, empresas públicas e privadas e instituições do terceiro setor para, por exemplo, discutir e apresentar demandas sociais, ambientais, econômicas e de

outros aspectos desta problemática em determinada localidade.

Teixeira et al. (2018) ainda destacam que a participação e o envolvimento dos diversos públicos de interesse nas decisões públicas deve ser mobilizada através da divulgação das atividades desenvolvidas no contexto da gestão de políticas públicas e de informações específicas deste processo em distintos recursos comunicativos.

Deste modo, para a mobilização social e divulgação das modalidades participativas instituídas na elaboração do PERS/TO, foram adotados pela SEMARH diversos veículos da mídia impressa, televisiva, radiofônica e digital, quais sejam: ofícios, convites, banners, folders, fundo de palco e jornais, emissoras de rádio e TV, além de portais, websites, email, vídeos para sites, jornais digitais e redes sociais (TOCANTINS, 2015).

Existe muita confusão conceitual quando se trata de mobilização social. Em muitos casos o termo é adotado como sinônimo de passeatas, manifestações públicas e concentração de pessoas em determinado local. Mas, na verdade, a mobilização ocorre em torno de um objetivo comum entre atores estatais e não estatais, e a partir disso decisões são tomadas e ações são executadas. O intuito disso é buscar resultados efetivos e eficazes para o enfrentamento de 


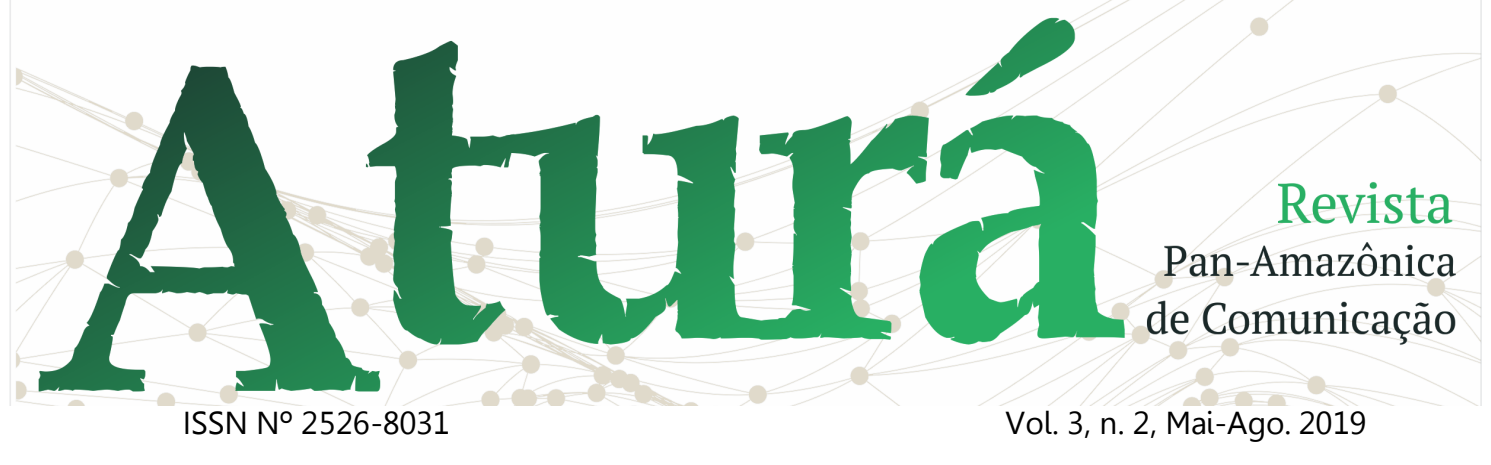

determinado problema (TORO; WERNECK, 2018).

Mobilização pode ser vista como um ato de comunicação que busca construir a democracia e a participação social em torno de discussões específicas da agenda pública. Neste sentido, as pessoas são chamadas, convocadas para participar de um processo de mobilização social, mas a escolha de participar diz respeito ao modo como cada indivíduo se sente representado no processo, seja como responsável ou não por provocar e realizar mudanças (TORO; WERNECK, 2018).

As atividades de comunicação arquitetadas para a mobilização das agências governamentais e grupos distintos da sociedade tendo em vista a participação destes na gestão e gerenciamento de resíduos sólidos devem apresentar dados e informações a respeito dos impactos sociais, econômicos e ambientais da destinação e disposição destes resíduos de modo inadequado. É a partir da exposição da problemática aos públicos de interesse em distintos veículos de comunicação que a participação destes nas arenas de debates públicos pode ser mobilizada (BARCIOTTE; SACCARO JUNIOR, 2012).

Assim, as estratégias de comunicação para a mobilização social devem orientar os indivíduos a respeito de um dado assunto em espaços de

interação institucionalizados, ou ainda criar espaços com esta finalidade, onde o diálogo livre deve ser a base das relações e interações entre os sujeitos, e a apreensão de novos significados e a troca de conhecimento neste âmbito, elaborado e reelaborado a partir das vivências da comunidade (HENRIQUES et al., 2007).

Para ocorrer a mobilização social é preciso explorar diferentes meios de comunicação da contemporaneidade e dispor de estratégias de comunicação adequadas ao contexto em que os grupos de interesse estão inseridos. Ainda a mobilização estabelece diversas relações com estes grupos de modo adquirir legitimidade pública (MAFRA, 2006).

Diante das discussões apresentadas, os veículos da mídia regional atuaram como divulgadores de dados e informações a respeito das modalidades de expressão e diálogo instituídas pela administração pública tocantinense com o intuito de mobilizar a participação dos municípios deste estado e outros agentes internos e externos durante a elaboração do respectivo plano de resíduos sólidos.

A globalização e o desenvolvimento das tecnologias de informação e comunicação trouxeram novas perspectivas para os veículos de comunicação regionais e locais, tais como abordagens voltadas para a valorização 


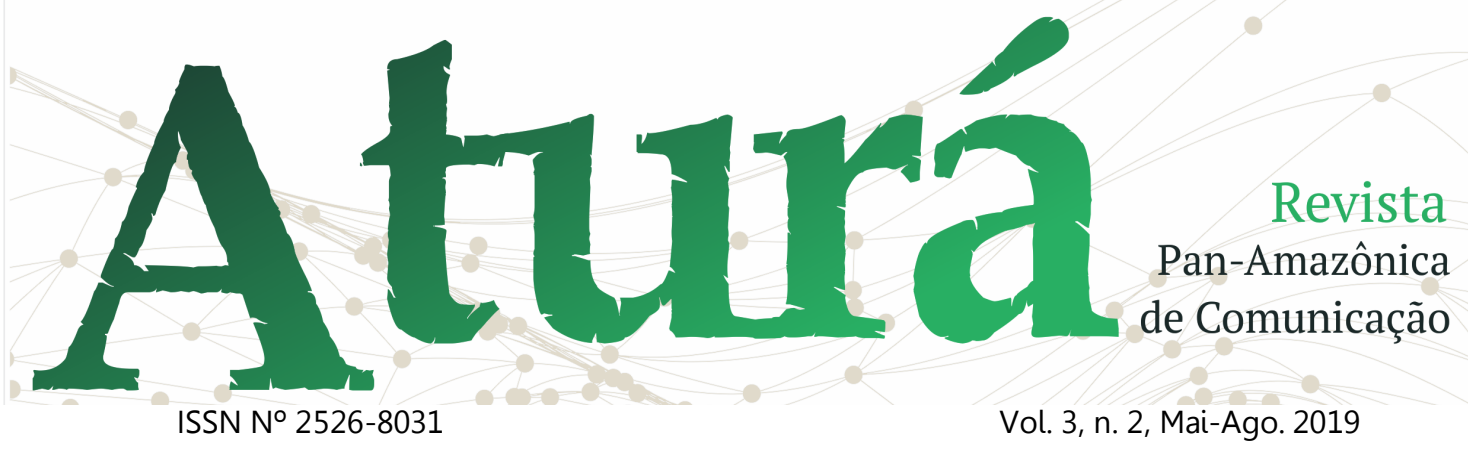

das identidades e culturas locais a partir de práticas cotidianas e mercadológicas (MENESES, 2015). Nota-se, portanto, que a aproximação entre as diversas sociedades e a inovação tecnológica deixaram contribuições significativas para o desenvolvimento e aprimoramento dos veículos de comunicação regionais e locais (LIMA, 2008; JERÓNIMO, 2015).

A mídia neste contexto adota a informação de proximidade (PERUZZO, 2005; JERÓNIMO, 2015). É este tipo de informação que garante maior representatividade local e regional (JERÒNIMO, 2015). Peruzzo (2005, p. 72) destaca que "os programas produzidos localmente são, principalmente, os jornalísticos a partir da realidade e dos acontecimentos locais, mas há também outros gêneros de programas, como debates e documentários". Para Camponez (2002) trata-se de um jornalismo que resulta de um forte compromisso com o território e com as pessoas que com ele se relacionam, geográfica ou afetivamente. Na visão de Jerónimo (2015), o que caracteriza a imprensa regional, não é o simples fato de ela estar localizada em dado local, mas as relações de proximidade com 0 território e a comunidade.

No âmbito dessas discussões, mídia regional refere-se a um conjunto de meios de comunicação existentes em uma área geográfica (RABAÇA; BARBOSA,
2001). Entende-se, no entanto, que a mídia local se define pelo conteúdo e pelo espaço geográfico, enquanto que a regional pela questão da difusão, isto é, envolve a própria região (LIMA, 2008).

Nos estudos de mídia regional, o termo território é um conceito essencial, e, nesta pesquisa, segue-se o que orienta Meneses (2015, p. 82): "Território em relação à mídia regional e local, portanto, é o espaço, físico ou virtual, em que os conteúdos gerados são dotados de identidade e de elementos de pertencimento dos atores sociais desse espaço".

\section{Material e métodos}

Esta pesquisa foi caracterizada como exploratória e de natureza qualitativa. Para Prodanov e Freitas (2013) a pesquisa exploratória consiste em manter maior familiaridade com a problemática estudada. Ainda estes mesmos autores apontam que em estudos qualitativos é levado em consideração a subjetividade dos sujeitos. Nesta pesquisa considerou-se a subjetividade do pesquisador diante do conteúdo estudado. Para a coleta de dados adotou-se a pesquisa documental.

A pesquisa documental pode envolver reportagens e legislações (PRODANOV; FREITAS, 2013). As pesquisas foram realizadas pela internet $\mathrm{e}$ 


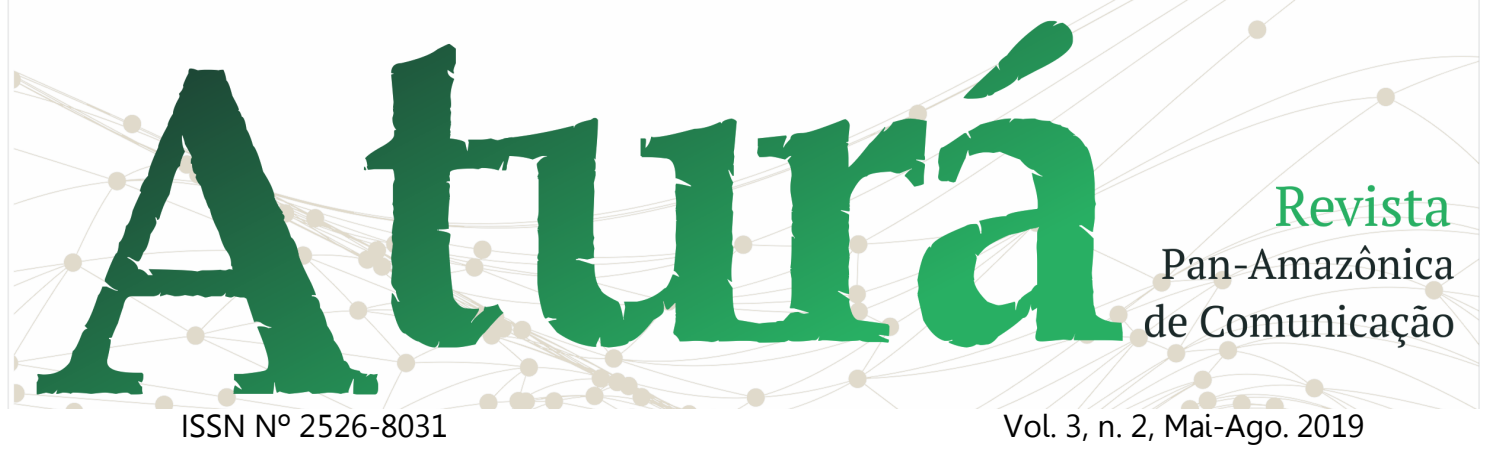

desenvolvidas a partir do conteúdo online publicado em sites.

A pesquisa considera dados $\mathrm{e}$ opiniões sobre a elaboração do Plano Estadual de Resíduos Sólidos do Tocantins publicados por veículos online da mídia regional, especificamente no município de Palmas, tendo em vista identificar os portais de notícias que publicaram conteúdos relacionados a este assunto, o quantitativo de material jornalístico publicado pelos portais de notícias e os momentos participativos retratados pelos veículos de comunicação.

Para a realização desta pesquisa, realizou-se um mapeamento dos veículos deste município através do site mapa da mídia no Tocantins ${ }^{2}$. Depois de identificados os veículos, a busca do material jornalístico ocorreu no próprio site do veículo através de palavras-chave relacionadas ao tema discutido: plano de resíduos sólidos, plano estadual de resíduos sólidos e resíduos sólidos. Aqueles que não continham material relacionado ao assunto foram eliminados. O período de busca determinado foi o de elaboração do plano de resíduos deste estado, de 2015 a 2017.

Deste modo, o levantamento de dados foi composto de 26 matérias jornalísticas publicadas pelos portais eletrônicos. No tratamento de dados, optou-se pela análise de conteúdo conforme três categorias específicas: oficinas técnicas, audiências públicas e seminário estadual de resíduos sólidos, bem como os seguintes critérios: préanálise, exploração do material jornalístico encontrado e tratamento dos resultados, inferência e interpretação (BARDIN, 1977).

\section{Análise e discussão dos dados coletados}

Dados da consulta realizada no site mapa da mídia no Tocantins aponta que de 21 veículos da mídia regional localizados em Palmas, cerca de 8 deles veicularam algum tipo de conteúdo online relacionados a elaboração do PERS/TO: T1 Notícias, Conexão Tocantins, Jornal do Tocantins, Portal Stylo, o Coletivo, Gospel Geral, Diário do Tocantins e o Jornal. Das 26 notícias disponibilizadas pelos veículos da mídia, cerca de 7 revelam informações sobre a realização das oficinas técnicas, sendo estas publicadas pelo T1 Notícias, Conexão Tocantins, Jornal do Tocantins e Portal Stylo. Os detalhes podem ser visualizados no quadro 1.

Quadro 1: Relação de portais de notícias de Palmas que veicularam informações sobre a elaboração do plano de resíduos e as matérias jornalísticas relacionadas as oficinas. Fonte: Elaborado pelo autor (2019).

\footnotetext{
${ }^{2}$ http://www.midiatocantins.com.br/
} 


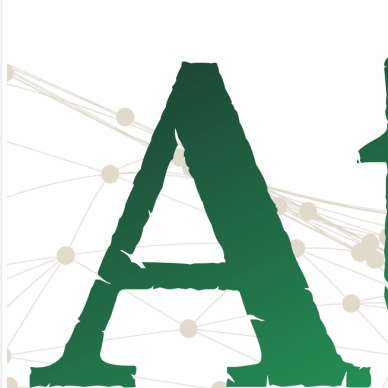

ISSN Nº 2526-8031

\section{Revista}

Pan-Amazônica

de Comunicação

Vol. 3, n. 2, Mai-Ago. 2019

\section{PORTAL \\ DE \\ NOTÍCIA}

T1

Notícias

Conexão

Oficinas para elaboração do plano

\section{MATÉRIAS}

estadual de resíduos sólidos são realizadas

Oficina regional para a elaboração do Plano Estadual de Resíduos Sólidos acontece nesta quarta-feira, em Palmas

Governo segue com as oficinas regionais para a elaboração do Plano Estadual de Resíduos Sólidos

Tocantins

Jornal do Tocantins

Governo segue com as Oficinas Portal Regionais para elaboração do Plano Stylo Estadual de Resíduos Sólidos

De acordo o material jornalístico destacado no quadro 1 , em matérias publicadas pelos veículos da mídia regional: T1 Notícias ${ }^{3}$, Conexão Tocantins

\footnotetext{
${ }^{3}$ https://www.t1noticias.com.br/
}

e Portal Stylo, nota-se que as oficinas técnicas de elaboração do PERS/TO são retratadas de modo bastante superficial, pois é destacado apenas a importância do plano para a gestão de resíduos sólidos do estado e a realização das oficinas técnicas nos municípios de Araguaína, Araguatins, Augustinópolis, Colinas, Goiatins, Tocantinópolis e Xambioá, mas sem especificar detalhes como data, horário e local de realização destas.

Apesar das matérias apontadas anteriormente não apresentarem detalhes específicos sobre a realização dos eventos, a simples leitura do material por atores sociais distintos, pode levar estes a procurarem por mais informações a respeito deste assunto nos veículos da mídia ou em outras fontes. No estudo de Silva; Alcântara e Pereira (2016), estes autores evidenciaram que a apresentação de notícias traduz em algum tipo de participação popular nas arenas de debates públicos sobre a implementação da política de resíduos sólidos.

Já em outra matéria publicada pelo Conexão Tocantins ${ }^{4}$, assim como apontado pelo conteúdo jornalístico disposto no quadro 1 , percebe-se que a mesma retrata da data, horário e local de realização da oficina técnica na regional de Palmas, assim como em Tocantinópolis. Um detalhe destacado

${ }^{4}$ https://conexaoto.com.br/ 


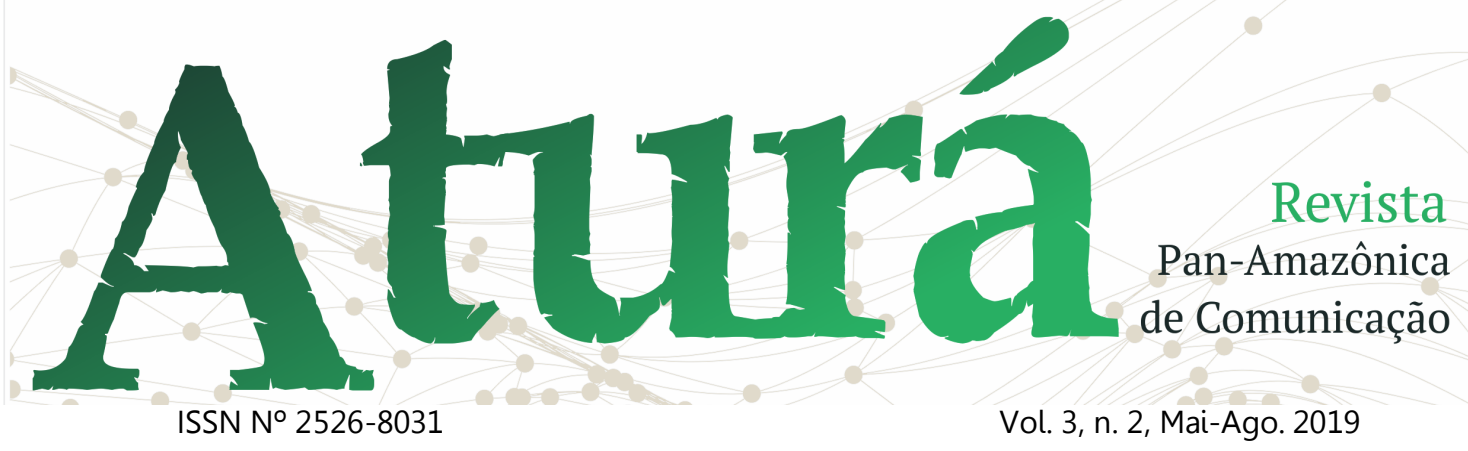

por este portal de notícias é o fato de ele ter apontado informações tanto de momentos antes como depois da realização da oficina em Tocantinópolis. Deste modo, cabe citar a pesquisa de Teixeira et al. (2018), pois estes autores apontam que as estratégias de mobilização social adotadas na elaboração do plano de resíduos sólidos da Baixada Santista coletaram informações relevantes para avaliar e complementar a construção deste.

Conforme exposto pelas notícias listadas do quadro 1 , na abordagem noticiosa do Jornal do Tocantins ${ }^{5}$, este veículo apenas apresentou dados sem especificidades das oficinas técnicas. $O$ Portal Stylo ${ }^{6}$ apresentou dados relacionados a análise do diagnóstico das oficinas técnicas e, posteriormente, a realização das audiências públicas em Araguaína, Gurupi e Palmas.

A análise do quadro demonstra que alguns portais de notícias veicularam algum tipo de informação sobre a realização das oficinas: T1 notícias, Conexão Tocantins, Jornal do Tocantins e Portal Stylo. Neste cenário, apenas as oficinas realizadas em Palmas e Tocantinópolis foram referenciadas pelos veículos da mídia regional. Isto representa 2 das 18 macrorregiões onde aconteceram oficinas. Nota-se, deste

\footnotetext{
${ }^{5}$ https://www.jornaldotocantins.com.br/

${ }^{6}$ http://www.portalstylo.com.br/
}

modo, que nem sempre existe material jornalístico visando a mobilização de cidadãos para participar das discussões públicas. Para Pressler e Amin (2017) ainda é perceptível ausência de processos de comunicação que busquem a mobilização das pessoas físicas e jurídicas para a questão dos resíduos sólidos.

Detalhes da composição das matérias jornalísticas mapeadas sobre as audiências públicas podem ser conferidos no quadro 2. Na pesquisa documental, encontrou-se um total de 11 matérias de 5 portais de notícias ( $\mathrm{T} 1$ Notícias, Conexão Tocantins, o Coletivo, Jornal do Tocantins e Portal Stylo) que retrataram do assunto.

As matérias publicadas pelo $\mathrm{T} 1$ notícias, assim como demonstrado pelo quadro 2, abordam horário, data e local das audiências ocorridas em Araguaína e Gurupi, e também a proposta destas que era de debater diretrizes, estratégias, metas e ações para a gestão de resíduos sólidos no estado.

As notícias retratadas pelo Conexão Tocantins, de acordo com o ilustrado pelo quadro 2 , retratam de detalhes das audiências públicas ocorridas em Palmas e Araguaína. Neste momento o foco das audiências era discutir a versão preliminar do PERS/TO. Na matéria que retratou de Palmas e de Araguaína, o portal disponibilizou link para acesso a esta versão. 


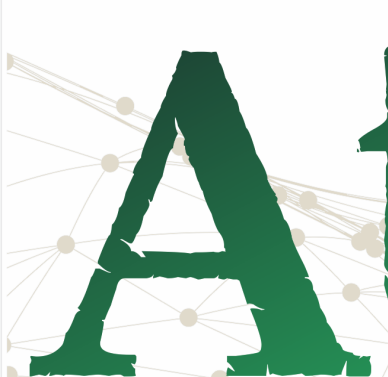

ISSN N $2526-8031$

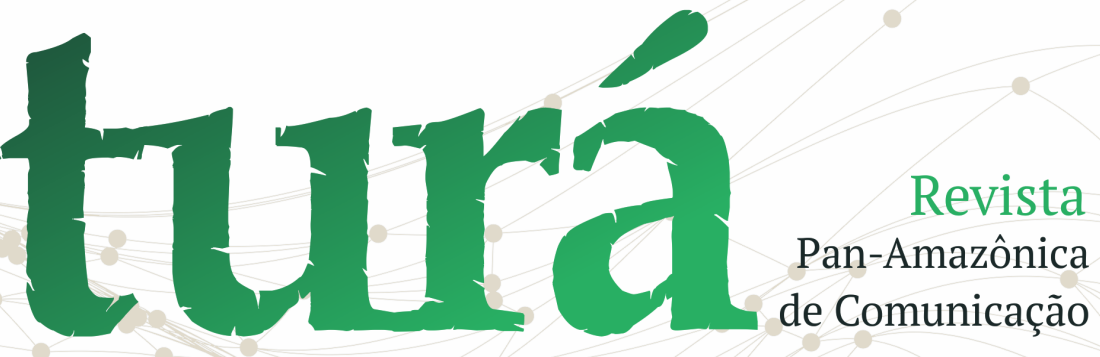

Vol. 3, n. 2, Mai-Ago. 2019
Quadro 2. Relação de portais de notícias de Palmas que veicularam informações sobre a elaboração do plano de resíduos e as matérias jornalísticas relacionadas as audiências públicas. Fonte: Elaborado pelo autor (2019).

\begin{tabular}{|c|c|}
\hline $\begin{array}{l}\text { PORTAL } \\
\text { DE } \\
\text { NOTÍCIA }\end{array}$ & MATÉRIAS \\
\hline \multirow{2}{*}{$\begin{array}{l}\text { T1 } \\
\text { Notícias }\end{array}$} & $\begin{array}{l}\text { Plano estadual de resíduos sólidos } \\
\text { será tema de audiências }\end{array}$ \\
\hline & Plano estadual de resíduos sólidos \\
\hline \multirow{3}{*}{$\begin{array}{l}\text { Conexão } \\
\text { Tocantins }\end{array}$} & $\begin{array}{l}\text { Ciclo de audiências sobre Plano } \\
\text { Estadual de Resíduos Sólidos será } \\
\text { finalizado em Palmas }\end{array}$ \\
\hline & $\begin{array}{l}\text { Araguaína é sede de audiência } \\
\text { pública sobre plano estadual de } \\
\text { resíduos sólidos }\end{array}$ \\
\hline & $\begin{array}{l}\text { Plano Estadual de Resíduos Sólidos } \\
\text { será tema de três audiências públicas }\end{array}$ \\
\hline $\begin{array}{l}\text { O } \\
\text { Coletivo }\end{array}$ & $\begin{array}{l}\text { Governo realiza audiências públicas } \\
\text { sobre Plano Estadual de Resíduos } \\
\text { Sólidos }\end{array}$ \\
\hline \multirow{2}{*}{$\begin{array}{l}\text { Jornal do } \\
\text { Tocantins }\end{array}$} & $\begin{array}{l}\text { Plano sobre resíduos recebe } \\
\text { contribuições }\end{array}$ \\
\hline & Gestão de resíduos em debate \\
\hline \multirow{3}{*}{$\begin{array}{l}\text { Portal } \\
\text { Stylo }\end{array}$} & $\begin{array}{l}\text { Audiências sobre Plano Estadual de } \\
\text { Resíduos Sólidos é finalizado nesta } \\
\text { terça-feira em Palmas }\end{array}$ \\
\hline & $\begin{array}{l}\text { Araguaína recebe audiência pública } \\
\text { sobre Plano Estadual de Resíduos } \\
\text { Sólidos }\end{array}$ \\
\hline & $\begin{array}{l}\text { Gurupi recebe segunda audiência do } \\
\text { Plano de Resíduos Sólidos }\end{array}$ \\
\hline
\end{tabular}

No conteúdo divulgado pelo o Coletivo, representado no quadro 2, destaca a realização das audiências públicas em Araguaína, Gurupi e Palmas de modo geral, mas especifica detalhes como data, horário e local da audiência realizada em Araguaína. As notícias sobre as audiências de Gurupi e Palmas não apresentaram peculiaridades como horário e local.

A matéria jornalística apresentada pelo Jornal do Tocantins, disposta no quadro 2, retratou detalhes minuciosos da audiência realizada em Araguaína. O conteúdo divulgado pelo Portal Stylo apontou data, horário e local da realização das audiências de Araguaína, Gurupi e Palmas, e nas discussões sobre este último município também disponibilizou link para acesso a versão preliminar do PERS/TO. Percebe-se que o Portal Stylo conseguiu manter uma sequência na divulgação de informações sobre as audiências.

Ainda que a mídia traga recortes dos processos de diálogo e expressividade criados na elaboração do PERS/TO, observa-se que as notícias, principalmente aquelas que retratam das oficinas e das audiências, em sua maioria, não retratam da sequência dos acontecimentos. $\mathrm{Na}$ pesquisa desenvolvida por Silva; Alcântara e Pereira (2016), que retrata de uma análise realizada a partir de notícias publicadas em veículos da mídia de Lavras - MG relacionadas a resíduos sólidos, estes autores identificaram algo parecido com o encontrado aqui, pois tanto este como 


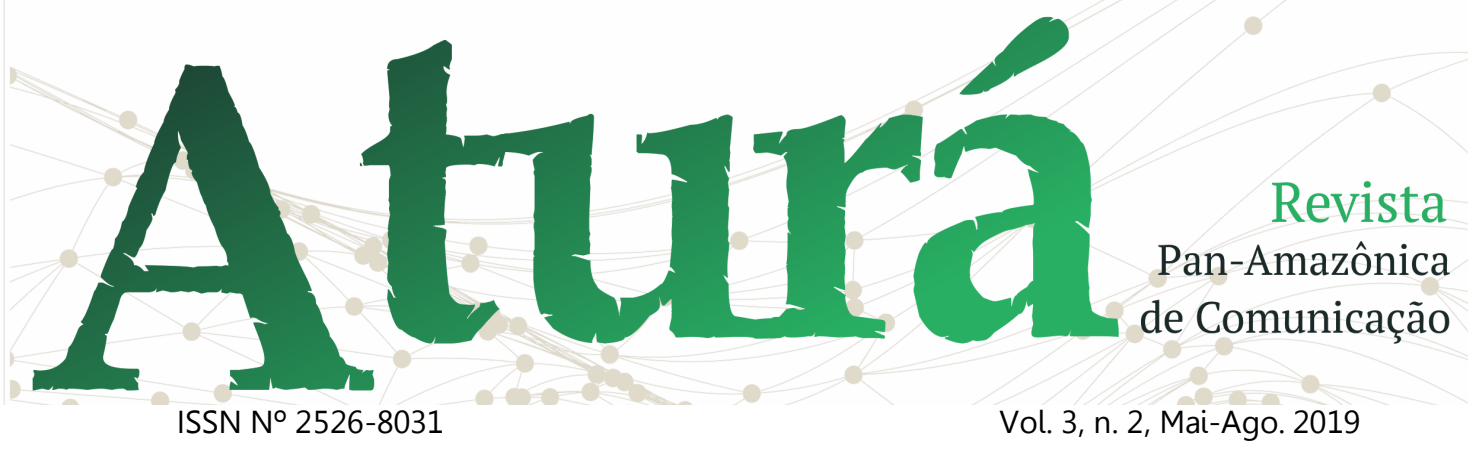

o outro estudo destaca que os portais de notícias não dão sequência aos processos em trâmite.

No levantamento de dados foi encontrado 7 notícias publicadas relacionadas ao seminário estadual de resíduos sólidos, sendo os portais Gospel Geral, Diário do Tocantins, Conexão Tocantins, o Jornal e o Jornal do Tocantins responsáveis pelas publicações. Detalhes podem ser verificados no quadro 3.

Analisando o conteúdo das matérias disponibilizadas no quadro 3, pode-se observar que aquelas publicadas pelo Gospel $\mathrm{Geral}^{7}$ e o Jornal ${ }^{8}$ retrataram da realização do seminário estadual de resíduos sólidos e que este seria lançado na semana de meio ambiente, bem como da relevância do plano para a gestão de resíduos sólidos tocantinense, porém apresentaram dados depois de realizado o seminário e não informou horário e local.

No conteúdo publicado pelo Diário do Tocantins ${ }^{9}$, de acordo com o apontado pelo quadro 3, este divulgou a data, horário e local de realização do seminário, a parceria da SEMAR, do Ministério do Meio Ambiente (MMA), além da participação da Agência Tocantinense de Saneamento (ATS), mas

\footnotetext{
7 https://www.gospelgeral.com.br/

${ }^{8} \mathrm{http} / / /$ www.ojornal.net/

${ }^{9}$ https://diariodotocantins.com.br/
}

também retratou destes detalhes após a realização do seminário.

Quadro 3. Relação de portais de notícias de Palmas que veicularam informações sobre a elaboração do plano de resíduos e as matérias jornalísticas relacionadas ao seminário. Fonte: Elaborado pelo autor (2019).

\begin{tabular}{|l|l|}
$\begin{array}{l}\text { PORTAL DE } \\
\text { NOTÍCIA }\end{array}$ & \multicolumn{1}{|c}{ MATÉRIAS } \\
\hline $\begin{array}{l}\text { Gospel } \\
\text { Geral }\end{array}$ & $\begin{array}{l}\text { Governador comemora avanço na } \\
\text { política ambiental com Plano } \\
\text { Estadual de Resíduos Sólidos }\end{array}$ \\
\hline $\begin{array}{l}\text { Diário do } \\
\text { Tocantins }\end{array}$ & $\begin{array}{l}\text { Agência de Saneamento participa } \\
\text { do lançamento do Plano Estadual } \\
\text { de Resíduos Sólidos }\end{array}$ \\
\hline Conexão & $\begin{array}{l}\text { Governador comemora avanço na } \\
\text { política ambiental com Plano } \\
\text { Estadual de Resíduos Sólidos }\end{array}$ \\
\hline Tocantins & $\begin{array}{l}\text { Plano Estadual de Resíduos Sólidos } \\
\text { será apresentado nesta quarta- } \\
\text { feira }\end{array}$ \\
\hline O Jornal & $\begin{array}{l}\text { Governador comemora avanço na } \\
\text { política ambiental com Plano } \\
\text { Estadual de Resíduos Sólidos }\end{array}$ \\
\hline Jornal do & $\begin{array}{l}\text { Lançamento do Plano Estadual de } \\
\text { Resíduos Sólidos acontece amanhã }\end{array}$ \\
\hline Tocantins & $\begin{array}{l}\text { Gestores conhecem Plano de } \\
\text { Resíduos }\end{array}$ \\
\hline
\end{tabular}

O Conexão Tocantins apresentou a importância do plano para o enfrentamento da problemática de resíduos sólidos no estado e informações bastante específicas da realização do seminário como data, horário e local, bem como divulgou dados em momento posterior a este processo participativo e 


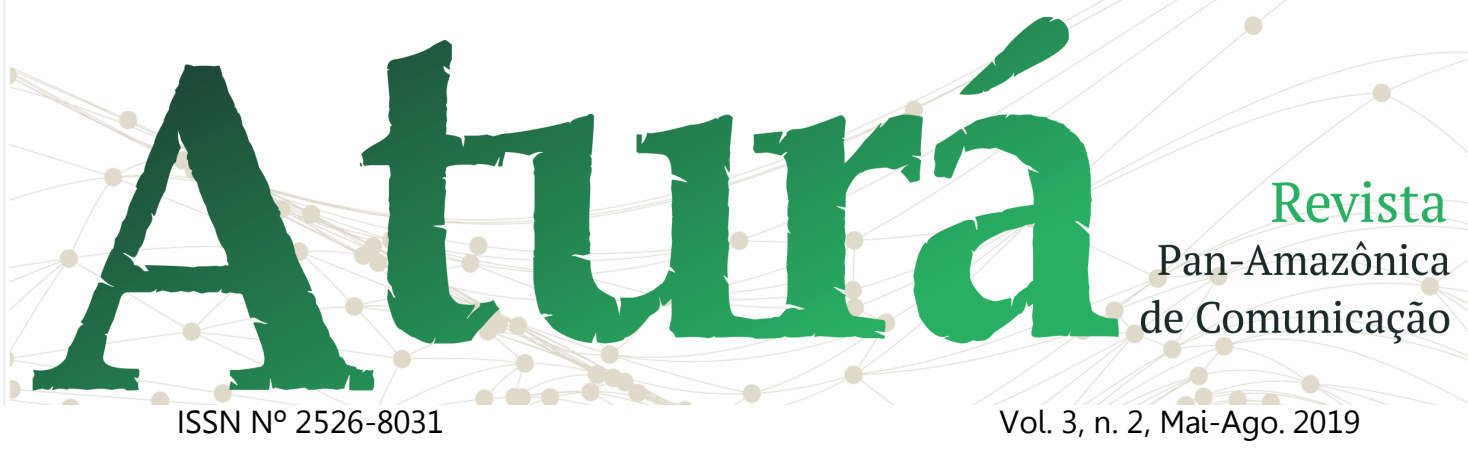

link para acesso ao plano. O Jornal do Tocantins também expôs material relacionado a data, horário e local para o das atividades do seminário, além de dados de momento posterior a este (ver quadro 3 ).

Teixeira et al. (2018) identificaram em sua pesquisa que ainda que exista um processo de mobilização social através de notícias para que os grupos da sociedade participem das decisões relacionadas a implementação da política pública de resíduos sólidos, é necessário que as agências governamentais após este processo continuem a mobilizar a participação destes na gestão e no gerenciamento de resíduos sólidos.

Depreende-se dos dados apresentados pelos quadros 1, 2 e 3 que apenas dois portais de notícias retrataram em algum momento das oficinas, audiências públicas e do seminário de resíduos sólidos: Conexão Tocantins e o Jornal do Tocantins. Os demais, noticiaram a respeito deste assunto duas ou até mesmo uma vez. Mesmo que estes portais trouxeram informações a respeito destes momentos, é importante lembrar que nem todas as oficinas e audiências foram retratadas.

\section{Considerações finais}

A elaboração do PERS/TO e as oficinas técnicas, audiências públicas e 0 seminário estadual de resíduos sólidos, momentos participativos instituídos pela SEMARH durante este processo, tendo em vista $O$ atendimento dos requisitos de participação e controle social dispostos pela PNRS representam o ponto de partida deste trabalho. Dessa forma, o artigo buscou discutir a elaboração deste plano a partir do material jornalístico publicado pela mídia regional localizada em Palmas, a fim de verificar a atuação dos veículos de notícias no que se trata de dados e informações relacionadas a estes processos participativos.

Assim, a análise dos dados permitiu observar que nem todos os veículos da mídia regional situados em Palmas divulgaram algo a respeito dos momentos participativos adotados durante a elaboração do PERS/TO. Apenas 8 (T1 Notícias, Conexão Tocantins, Jornal do Tocantins, Portal Stylo, o Coletivo, Gospel Geral, Diário do Tocantins e o Jornal) de um total de 21 apresentaram algo neste sentido.

A análise das matérias publicados pelos veículos da mídia demonstra que os conteúdos postados sobre as oficinas não apresentam sequência de realização destas. Apenas retratam destas em alguns momentos durante a elaboração deste. Em muitos casos não informam data, horário e local de realização destas. De modo geral, em casos específicos apresentam dados insuficientes e que abordam do assunto de maneira bastante 


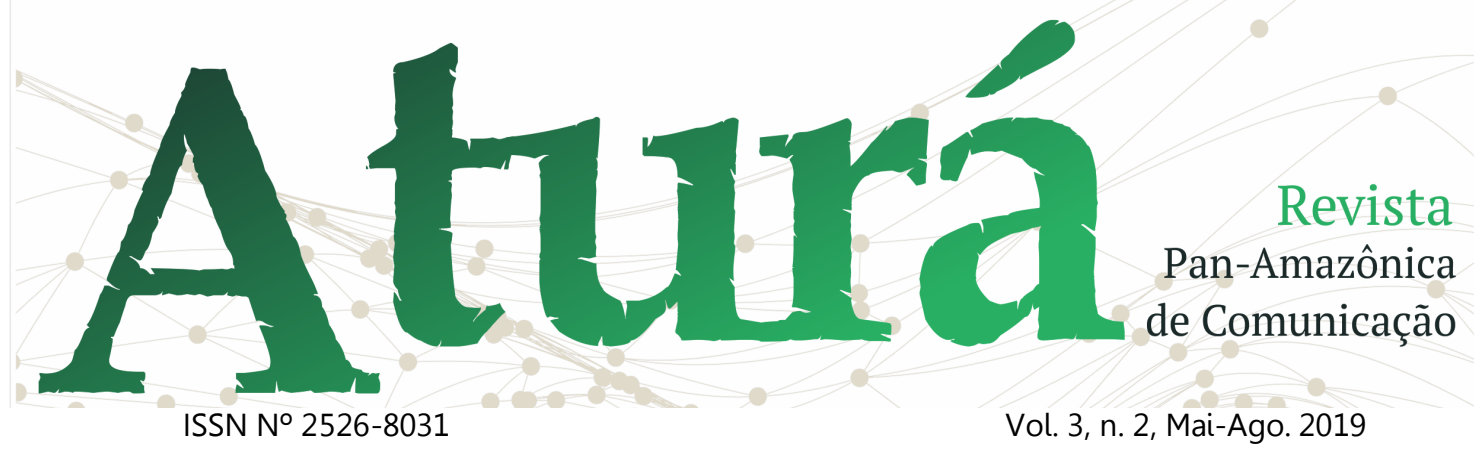

abrangente. Por fim, noticia somente a respeito das oficinas realizadas em Palmas e Tocantinópolis, isto é, 2 das 18 regionais.

Vale destacar que, as oficinas técnicas representam momentos em que diversas pessoas e agentes públicos se reúnem para apresentar propostas de melhorias, a situação e as distintas problemáticas vivenciadas no que diz respeito a questão dos resíduos sólidos em determinada localidade. A pluralidade de ideias contribui para um diagnóstico mais estruturado e que represente realidades distintas. Percebe-se, portanto, através da análise de dados, que os veículos da mídia não retrataram com bastante intensidade este assunto, principalmente por envolver dados empíricos de uma localidade para incluir no PERS/TO.

Em algumas notícias publicadas pelos veículos mapeados pelo estudo e que retratam das audiências públicas, ainda é notável que existe aqueles que apresentaram detalhes mais específicos sobre estes processos e outros que não. O Portal Stylo, por exemplo, divulgou dados a respeito das três audiências públicas. Outros ainda apresentaram um link de acesso a versão preliminar do PERS/TO disponibilizado durante a realização deste evento.

No material jornalístico publicado pela mídia regional, especificamente

relacionado ao seminário estadual de resíduos sólidos, observa-se que houve conteúdo disponibilizado que retratou da realização deste apenas após a sua realização e sem informações detalhadas.

Apesar de um total de 8 veículos se manifestarem em relação a elaboração do PERS/TO, é perceptível que apenas algumas matérias abordaram assuntos ligados aos processos participativos instituídos. O Conexão Tocantins e o Jornal do Tocantins em algum momento de tempo publicaram notícias sobre as oficinas, audiências e o seminário, os demais divulgaram informações sobre um ou dois destes acontecimentos.

Pelo exposto, nota-se que a mídia regional demonstrou pouca atuação durante a elaboração do $\mathrm{PERS} / \mathrm{TO}$, pois em alguns casos não apresentou detalhes da realização das oficinas técnicas, audiências públicas e do seminário. É notável a ausência de uma sequência detalhada dos acontecimentos apresentados. Em alguns casos apresentou a sequência das oficinas, mas não detalhou mais informações a respeito, e nem todas elas foram alvo de notícias. Para um próximo estudo, sugere-se uma análise do material jornalístico publicado por veículos da mídia regional de todo um estado (e não apenas de um único município) sobre a elaboração do seu plano de resíduos sólidos. 


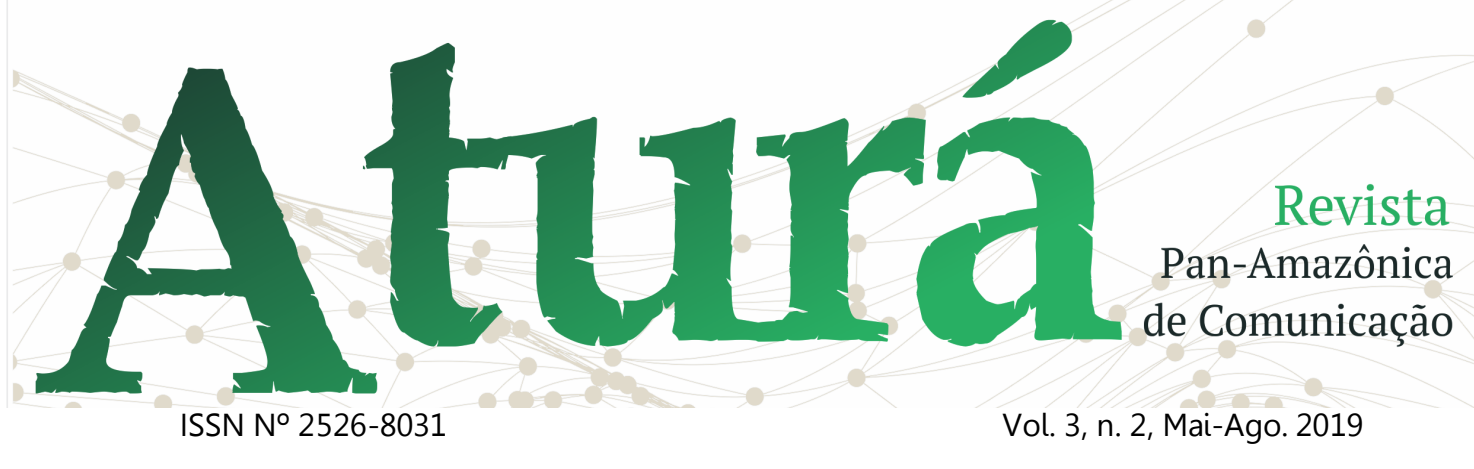

\section{Referências}

BARCIOTTE, M. L.; SACCARO JUNIOR, N. L. Sensibilização e mobilização dentro da Política Nacional de Resíduos Sólidos: desafios e oportunidades da educação ambiental. Brasília: IPEA, 2012.

BARDIN, L. Análise de conteúdo. Lisboa: Edições 70, 1977.

BRASIL, Presidência da república do. Lei $\mathrm{n}^{\circ}$ 12.305, de 2 de agosto de 2010. Institui a Política Nacional de Resíduos Sólidos; altera a Lei no 9.605, de 12 de fevereiro de 1998; e dá outras providências. Brasília, 2010.

GOMIDE, A. de Á.; PIRES, R. R. C. Capacidades estatais e democracia: A abordagem dos arranjos institucionais para análise de políticas públicas. In: GOMIDE, A. de Á.; PIRES, R. R. C. (Orgs.). Capacidades estatais e democracia: arranjos institucionais de políticas públicas. Brasília: Ipea, 2014. p. 15-30.

HENRIQUES, M. S.; BRAGA, C. S.; COUTO e SILVA, D. B. do.; MAFRA, R. L. M. Relações públicas em projetos de mobilização social: funções e características. In: HENRIQUES, M. S. (Org.). Comunicação e estratégias de mobilização social. 2 ed. Belo Horizonte: Autêntica, 2007. p. 17-32.

JERÓNIMO, P. Ciberjornalismode proximidade: Redaç̃̃es, jornalistas e notícias online. Portugal: LabCom.IFP, 2015.
LIMA, M. É. de O. Regionalização midiática: conceitos e exemplos. In: MARÇOLLA, Rosangela.; OLIVEIRA, Roberto Reis de. (orgs.). Estudos de mídia regional, local e comunitária. São Paulo: Arte \& Ciência, 2008. 246 p.

MAFRA, R. Entre o espetáculo, a festa e a argumentação: mídia, comunicação estratégica e mobilização social. Belo Horizonte: Autêntica Editora, 2006. 192p.

MENESES, V. D. O Brasil e os Brasis na televisão regional aberta. Tocantins: EDUFT, 2015.

OBSERVATÓRIO DOS LIXÕES. Diagnóstico municipal para a Política Nacional de Resíduos Sólidos, 2019. Disponível em: http://www.lixoes.cnm.org.br/. Acesso em: 10 ago. 2019.

OBSERVATÓRIO DOS LIXÕES. Obrigações estaduais para a Política Nacional de Resíduos Sólidos, 2019. Disponível em: http://www.lixoes.cnm.org.br/. Acesso em: 10 ago. 2019.

PERUZZO, C. M. K. Mídia regional e local: aspectos conceituais e tendências. Comunicação \& Sociedade, v. 26, n. 43 , p. 67-84, 1o. sem. 2005.

PIRES, R.; VAZ, A. Participação social como método de governo? Um mapeamento das "interfaces socioestatais" nos programas federais. Brasília: IPEA, 2012. 


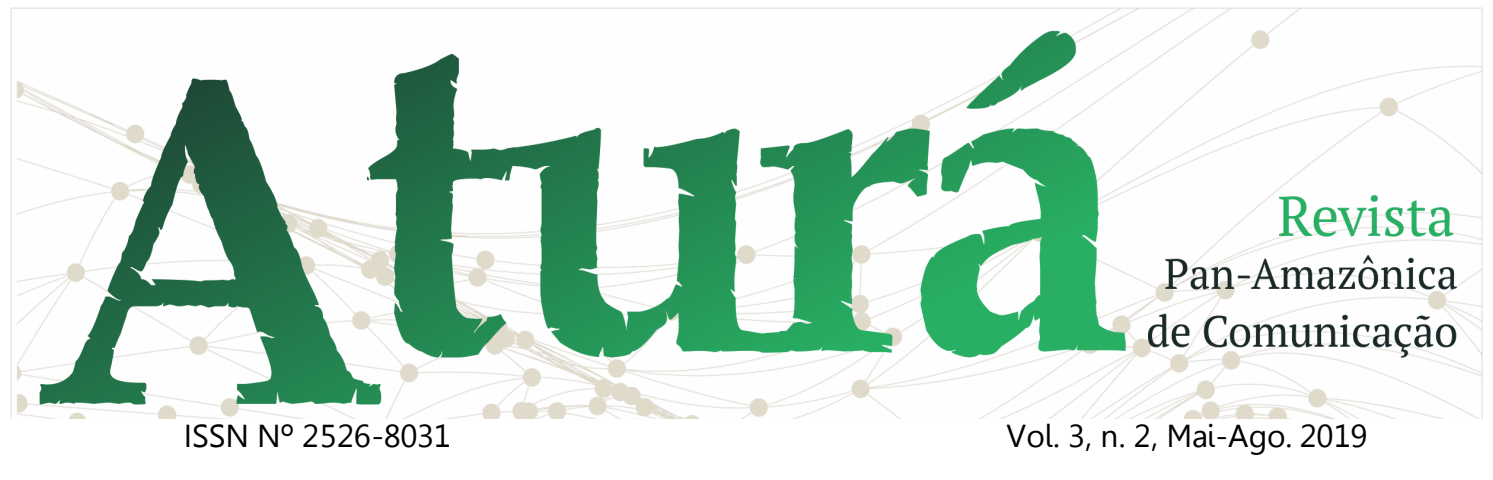

PRESSLER, N.; AMIN, V. do. S. F. Comunicação de interesse público e ciberativismo: as ações de sustentabilidade da comunidade virtual Mapa do lixo - Belém (PA) - Amazônia Comunicação \& Inovação, v. 18 , n. 37 , p. 84-102, mai/ago. 2017.

PRODANOV, C. C.; FREITAS, E. C. de. Metodologia do trabalho: métodos e técnicas da pesquisa e do trabalho acadêmico. 2 ed. Novo Hamburgo: Feevale, 2013.

RABAÇA, C. A.; BARBOSA, G. G. Dicionário de Comunicação. 3. ed. Rio de Janeiro: Campus, 2001.

SILVA, É. A. F.; ALCÂNTARA, V. de C.; PEREIRA, J. R. Governança e esfera pública sobre resíduos sólidos urbano no âmbito municipal. Administração Pública e Gestão Social, v. 8, n. 3, p. 137-146 jul./set. 2016.

TEIXEIRA, C. E.; IKEMATSUB, P.; MACEDO, L. dos S.; FREITAS, F. S. J. de.; MENEGHELLO, F. F.; MARQUES, A. L. B.; FERREIRA, M. A.; ROMÃO, G. A. R.; BERNARDINO, R. A. F. Mobilização social e comunicação em políticas públicas: o caso do Plano Regional de Gestão Integrada de Resíduos Sólidos da Baixada Santista (PRGIRS/BS). Revista IPT, v.2, n.8, p. 14-36, ago. 2018.

TORO, J. B.; WERNECK, N. M. D. Mobilização social: um modo de construir a democracia e a participação. São Paulo: Autêntica, 2018. 